\title{
PRACTICE PARAMETER: DIAGNOSIS OF DEMENTIA (AN EVIDENCE-BASED REVIEW)
}

\author{
Report of the Quality Standards Subcommittee of the American Academy of Neurology
}

\author{
D.S. Knopman, MD; S.T. DeKosky, MD; J.L. Cummings, MD; H. Chui, MD; J. Corey-Bloom, MD, PhD; \\ N. Relkin, MD, PhD; G.W. Small, MD; B. Miller, MD; and J.C. Stevens, MD
}

\begin{abstract}
Article abstract-Objective: To update the 1994 practice parameter for the diagnosis of dementia in the elderly. Background: The AAN previously published a practice parameter on dementia in 1994. New research and clinical developments warrant an update of some aspects of diagnosis. Methods: Studies published in English from 1985 through 1999 were identified that addressed four questions: 1) Are the current criteria for the diagnosis of dementia reliable? 2) Are the current diagnostic criteria able to establish a diagnosis for the prevalent dementias in the elderly? 3) Do laboratory tests improve the accuracy of the clinical diagnosis of dementing illness? 4) What comorbidities should be evaluated in elderly patients undergoing an initial assessment for dementia? Recommendations: Based on evidence in the literature, the following recommendations are made. 1) The DSM-III-R definition of dementia is reliable and should be used (Guideline). 2) The National Institute of Neurologic, Communicative Disorders and Stroke-AD and Related Disorders Association (NINCDS-ADRDA) or the Diagnostic and Statistical Manual, 3rd edition, revised (DSM-IIIR) diagnostic criteria for AD and clinical criteria for Creutzfeldt-Jakob disease (CJD) have sufficient reliability and validity and should be used (Guideline). Diagnostic criteria for vascular dementia, dementia with Lewy bodies, and frontotemporal dementia may be of use in clinical practice (Option) but have imperfect reliability and validity. 3) Structural neuroimaging with either a noncontrast CT or MR scan in the initial evaluation of patients with dementia is appropriate. Because of insufficient data on validity, no other imaging procedure is recommended (Guideline). There are currently no genetic markers recommended for routine diagnostic purposes (Guideline). The CSF 14-3-3 protein is useful for confirming or rejecting the diagnosis of CJD (Guideline). 4) Screening for depression, $\mathrm{B}_{12}$ deficiency, and hypothyroidism should be performed (Guideline). Screening for syphilis in patients with dementia is not justified unless clinical suspicion for neurosyphilis is present (Guideline). Conclusions: Diagnostic criteria for dementia have improved since the 1994 practice parameter. Further research is needed to improve clinical definitions of dementia and its subtypes, as well as to determine the utility of various instruments of neuroimaging, biomarkers, and genetic testing in increasing diagnostic accuracy.
\end{abstract}

NEUROLOGY 2001;56:1143-1153

Introduction. Mission statement. The Quality Standards Subcommittee of the American Academy of Neurology (AAN) is charged with developing practice parameters for physicians. This evidence-based review addresses major issues in the diagnosis of dementia.

Background and justification. Dementia is a common disorder in the elderly, involving as many as $10 \%$ of those over 65 years of age. The AAN previously published a practice parameter on dementia in 1994, ${ }^{1}$ and since that time many new clinical and research developments have occurred. The purpose of the current practice parameter is to highlight and to update major areas of current interest and investigation in the diagnosis of dementia in the elderly. It is not intended to serve as a comprehensive review of the differential diagnosis of dementia.

\footnotetext{
The appointment of authors for this guideline was done in cooperation with the Alzheimer's Association and overlaps significantly with the membership of the Medical and Scientific Advisory Council and the Board of Directors of the association. The Alzheimer's Association agrees with the content of this paper in all important regards.

This guideline has been endorsed by the American Association of Neuroscience Nurses and the American Geriatrics Society.

From the Department of Neurology (Dr. Knopman), Mayo Clinic, Rochester, MN; Departments of Neurology and Psychiatry (Dr. DeKosky),

University of Pittsburgh, PA; Departments of Neurology and Psychiatry \& Biobehavioral Science (Dr. Cummings), University of California at Los Angeles; Department of Neurology (Dr. Chui), University of Southern California, Los Angeles; Department of Neurosciences (Dr. Corey-Bloom), University of California at San Diego; Department of Neurology and Neuroscience (Dr. Relkin), New York Presbyterian-Weill Cornell Medical College; Neuropsychiatric Institute and Hospital (Dr. Small), University of California at Los Angeles; Department of Neurology (Dr. Miller), University of California at San Francisco; Lutheran Medical Office (Dr. Stevens), Fort Wayne, IN.

Approved by the AAN Quality Standards Subcommittee, November 11, 2000. Approved by the AAN Practice Committee January 6, 2001. Approved by the AAN Board of Directors February 24, 2001.

Received July 6, 2000. Accepted in final form February 2, 2001.
}

Copyright (C) 2001 by AAN Enterprises, Inc. 
Clinical question statement. The Diagnosis of Dementia Committee reviewed the issues, problems, and challenges related to the diagnosis of dementia. Based on work that has been published since 1994, the Committee formulated four questions to be addressed in the practice parameter:

1. Are the current criteria for the diagnosis of dementia reliable?

2. Are current diagnostic criteria sufficiently accurate to establish a diagnosis for the prevalent dementias in the elderly?

3. Do laboratory tests improve the accuracy of the clinical diagnosis of dementing illness?

4. What comorbidities should be evaluated in elderly patients undergoing an initial assessment for dementia?

Process. Panel selection. A group of clinicians from various disciplines with extensive experience in diagnosing and caring for patients with dementia was assembled. The group was charged with focusing on the diagnosis of dementia. Committee members disclosed any real or potential conflicts of interest. Other work groups formulated practice parameters on the detection of dementia ${ }^{1}$ and the management of dementia. ${ }^{2}$

Literature review process. A literature search was conducted using MEDLINE, Excerpta Medica, and BIOSIS. The search included articles published from January 1985 through November 1999. The search strategy sought only studies published in English and studies on human disease. The principal search term was dementia. Other terms entered into the search included neuroimaging, diagnostic techniques, diagnostic imaging, biologic markers, CSF, diagnostic errors, differential diagnosis, and neuropsychologic tests. The original search yielded 1,175 articles of which approximately 300 articles were identified as relevant to our search questions. For articles on AD, we included only those based on more than 25 patients. For the less common dementias there was no minimal sample size. An additional 300 articles not identified by the literature search strategy, including ones published after the initial search was conducted, were submitted by committee members or obtained from bibliographies of articles identified in the search.

Each article was classified based on the quality of evidence (Class I through IV, table 1). After review of the evidence, recommendations were drafted, reviewed by all committee members, and identified as a Practice Standard, Guideline, or Option (table 2). When appropriate, data on specificity, sensitivity, and other numerical measures of diagnostic precision were extracted from the articles and placed in tables. Final inclusion of articles in this Practice Parameter was based on consensus of the Committee that they were relevant and informative in consideration of the four questions.

In addition to the review and final approval by the Quality Standards Subcommittee and the Practice Committee of the AAN, this Practice Parameter was reviewed by AAN members who had identified themselves as interested reviewers, by the Geriatric and Behavioral Neurology Sections of the AAN, by representatives of the American Geriatrics Society, and by representatives of the Alzheimer's Association.

Analysis of the evidence. Are the current criteria for the diagnosis of dementia reliable? The diagnostic formulations of dementia that are the most widely used in North America are based on definitions contained in the National Institute of Neurologic, Communicative Disorders and Stroke-AD and Related Disorders Association (NINCDS-ADRDA) Work Group, ${ }^{2}$ the Diagnostic and Statistical Manual, 3rd edition, revised (DSM-IIIR), ${ }^{3}$ and the Diagnostic and Statistical Manual, 4th edition (DSM-IV). ${ }^{4}$ The DSM-IIIR states:

The essential feature of Dementia is impairment in short- and long-term memory, associated with impairment in abstract thinking, impaired judgment, other disturbances of higher cortical function, or personality change. The disturbance is severe enough to interfere significantly with work or usual social activities or relationships with others. The diagnosis of Dementia is not made if these symptoms occur. . .in Delirium. . .

The DSM-IIIR definition of dementia has good to very good reliability (kappa's ranging from 0.5 to 0.9$).^{5-7}$ The closely related NINCDS-ADRDA and DSM-IV definitions of dementia have not been subjected to assessment of reliability.

\section{Practice recommendations.}

The DSM-IIIR definition of dementia, which is identical to the DSM-IV definition, is reliable and should be used routinely (Guideline).

\section{Are current diagnostic criteria able to establish a diagnosis for the prevalent dementias?}

Alzheimer's disease. The reliability of the diagnosis of AD is moderate (generalized kappa's in the 0.51 to 0.73 range) in Class II studies. ${ }^{8-10}$ When standardized clinical diagnostic criteria are used, interrater reliability ${ }^{6}$ and consistency of diagnosis between the initial visit and 1-year follow-up is high $\left(95 \%\right.$ in Forette $\left.{ }^{11}\right)$.

There are 13 studies, 3 Class I ${ }^{12-14}$ and 10 Class II, ${ }^{9,15-22}$ that have addressed the diagnostic accuracy of the clinical diagnosis of AD using neuropathologic confirmation as the "gold standard." Both the DSM-IIIR "Dementia of the Alzheimer type" (DAT) and the NINCDS-ADRDA "probable" AD definitions achieved either good sensitivity (average across cited studies $=81 \%$, range 49 to $100 \%$ ) for AD at the expense of specificity (average across cited studies $=70 \%$, range 47 to $100 \%$ ) or vice versa in the majority of the cited studies. A diagnosis of "possible" AD achieved very high 
Table 1 Classification of evidence

\begin{tabular}{|c|c|c|}
\hline Class & & Description \\
\hline I & \multicolumn{2}{|r|}{$\begin{array}{l}\text { Evidence provided by a well designed prospective study in a broad spectrum of persons with the suspected condition, using a "gold } \\
\text { standard" for case definition, in which test is applied in a blinded evaluation, and enabling the assessment of appropriate tests of } \\
\text { diagnostic accuracy. }\end{array}$} \\
\hline II & \multicolumn{2}{|r|}{$\begin{array}{l}\text { Evidence provided by a well designed prospective study of a narrow spectrum of persons with the suspected condition, or a well } \\
\text { designed retrospective study of a broad spectrum of persons with an established condition (by "gold standard") compared with a } \\
\text { broad spectrum of controls, in which test is applied in blinded evaluation, and enabling the assessment of appropriate tests of } \\
\text { diagnostic accuracy. }\end{array}$} \\
\hline III & \multicolumn{2}{|r|}{$\begin{array}{l}\text { Evidence provided by a retrospective study in which either persons with the established condition or controls are of a narrow spectrum, } \\
\text { and in which test is applied in a blinded evaluation. }\end{array}$} \\
\hline IV & \multicolumn{2}{|r|}{$\begin{array}{l}\text { Any design in which test is not applied in blinded evaluation OR evidence provided by expert opinion alone or in descriptive case series } \\
\text { (without controls). }\end{array}$} \\
\hline \multicolumn{3}{|c|}{ Table 2 Definitions for practice recommendations based on classification of evidence } \\
\hline \multicolumn{2}{|c|}{ Recommendation } & Description \\
\hline \multicolumn{2}{|c|}{ Standard } & $\begin{array}{l}\text { Principle for patient management that reflects a high degree of clinical certainty (usually this requires Class I evidence that } \\
\text { directly addresses the clinical question, or overwhelming Class II evidence when circumstances preclude randomized } \\
\text { clinical trials). }\end{array}$ \\
\hline \multicolumn{2}{|c|}{ Guideline } & $\begin{array}{l}\text { Recommendation for patient management that reflects moderate clinical certainty (usually this requires Class II evidence or } \\
\text { a strong consensus of Class III evidence). }\end{array}$ \\
\hline \multirow{2}{*}{\multicolumn{2}{|c|}{$\begin{array}{l}\text { Practice Option } \\
\text { Practice Advisory }\end{array}$}} & Strategy for patient management for which the clinical utility is uncertain (inconclusive or conflicting evidence or opinion). \\
\hline & & $\begin{array}{l}\text { Practice recommendation for emerging and/or newly approved therapies or technologies based on evidence from at least } \\
\text { one Class I study. The evidence may demonstrate only a modest statistical effect or limited (partial) clinical response, or } \\
\text { significant cost-benefit questions may exist. Substantial (or potential) disagreement among practitioners or between } \\
\text { payers and practitioners may exist. }\end{array}$ \\
\hline
\end{tabular}

sensitivity (average across 4 studies $=93 \%$, range 85 to $96 \%$ ) but at the price of specificity (average across 4 studies $=$ $48 \%$, range 32 to $61 \%),{ }^{13,14,17,22}$ reflecting the many features that non-AD dementias share with AD.

Vascular dementia (VAD). Four criteria for vascular dementia that are currently used include the State of California AD Diagnostic and Treatment Centers criteria (the "California" criteria), ${ }^{23}$ the National Institute of Neurologic Disorders and Stroke and the Association Internationale pour la Recherche et l'Enseignement en Neurosciences (NINDS-AIREN) criteria, ${ }^{24}$ the Hachinski Ischemic Score (HIS) as modified by Rosen, ${ }^{25,26}$ and those found in DSM-IV. ${ }^{4}$ In studies that compared clinical diagnoses and neuropathologic findings, the NINDS-AIREN and the California criteria (as well as DSM-IIIR) had very low sensitivity but higher specificity. Only one Class I study ${ }^{12}$ reported the sensitivity (43\%) and specificity (95\%) of a published criteria, NINDS-AIREN, for VAD. Four Class II studies with patient samples drawn from referral cohorts ${ }^{15-17,27,28}$ reported sensitivity and specificity of the diagnosis of vascular dementia with any criteria. With one exception, their results had the same diagnostic accuracy as the population-based studies, with low sensitivity (average across 5 studies $=50 \%$, range 20 to 89\%) but higher specificity (average across 5 studies $=87 \%$, range 64 to $98 \%$ ) for the HIS, DSM-IIIR, NINDS-AIREN, or California clinical criteria. A retrospective (Class II) study ${ }^{27}$ in which the HIS showed better sensitivity and specificity (both $89 \%$ ) was the one analysis of six in which the diagnosis of vascular dementia appeared both sensitive and specific.

Recent neuropathologic analyses ${ }^{12,14}$ offer a perspective on the difficulty in correctly diagnosing cerebrovascular pathology in dementia. Rather than considering vascular dementia as simply present or absent, these studies distinguished between "some or any" vascular lesions versus "pure" vascular pathology, i.e., the circumstance in which vascular pathology was both sufficient to account for cognitive symptoms and unaccompanied by other pathology. Some vascular pathology exists in 29 to $41 \%$ of dementia cases coming to autopsy in population-based cohorts, even though pure vascular pathology accounted for dementia in only 9 to $10 \% .^{12,14}$ The Hachinski Ischemic Score, while lacking neuroimaging criteria, may be more suitable for identifying the majority of dementia patients with vascular dementia, i.e., those with at least some cerebrovascular pathology, ${ }^{27}$ because of the low sensitivity of the NINDS-AIREN and California criteria. $^{12,15-17,28}$

Dementia with Lewy bodies (DLB). DLB has been defined clinically by the presence of dementia, gait/balance disorder, prominent hallucinations and delusions, sensitivity to traditional antipsychotics, and fluctuations in alertness. ${ }^{29}$ Two Class II studies evaluated the interrater reliability of the diagnosis of DLB based on the Consortium for DLB diagnostic criteria ${ }^{29}$ and found it to be relatively low. ${ }^{10,30}$

One Class I study ${ }^{12}$ investigated the diagnostic accuracy of DLB criteria against neuropathologic findings and found that sensitivity was low (22\%) but specificity (100\%) was high. Five Class II studies also showed low sensitivities (average across 5 studies $=58 \%$, range 34 to $75 \%$ ) but higher specificities (average across 5 studies $=87 \%$, range 71 to $94 \%$ ) for the diagnostic criteria of Consortium for DLB. ${ }^{10,30-33}$ In a prospective clinical study based on a DLB case registry with neuropathologically confirmed cases, hallucinations, depression, delusions, and delusional misidentification were all significantly higher in patients with DLB than AD. ${ }^{34}$ However, all of these features occurred in patients with AD 
as well. The presence of visual hallucinations and delusional misidentification as early symptoms showed sensitivities and specificities of $>50 \%$ but $<75 \%$. In another study, the clinical diagnosis of DLB was confirmed in only 5 of 10 cases at postmortem examination. ${ }^{35}$ The lack of specificity of the DLB clinical diagnosis appeared attributable to an equivalent amount of spontaneous extrapyramidal disturbance between the five cases with DLB at autopsy and the five without DLB at autopsy (four with $\mathrm{AD}$, one with progressive supranuclear palsy). ${ }^{35}$

Prominent deficits in attention, profound deficits in visuo-constructional skills, and relative sparing of memory are the neuropsychologic features of DLB. ${ }^{36,37}$ However, neuropsychologic tests do not reliably differentiate DLB from either AD or VAD. ${ }^{37}$ Similarly, even though patients with DLB show less temporal lobe atrophy on MRI than do patients with $\mathrm{AD}^{38}$ and more hypoperfusion in the occipital lobes ${ }^{39}$ neuroimaging has not proven successful in differentiating DLB from $\mathrm{AD}$.

Frontotemporal dementia (FTD). FTD is less common than AD, VAD, or DLB,${ }^{14,17,40}$ particularly in very elderly dementia cohorts. An autopsy-based Class II study (using retrospective clinical diagnoses determined from review of medical records) showed that most patients with FTD fulfill diagnostic criteria for AD. ${ }^{41}$ In contrast, a Class II study without autopsy confirmation ${ }^{42}$ found that the Lund-Manchester criteria ${ }^{43}$ (an earlier version of the Consensus diagnostic criteria for FTD ${ }^{44}$ ) differentiated $100 \%$ of FTD and AD patients. Early loss of personal awareness, early loss of social awareness, hyperorality, and stereotyped, perseverative behavior were somewhat sensitive (63 to $73 \%$ ) and highly specific (97 to 100\%) for differentiating the two conditions. ${ }^{42}$

Neuropsychologic test profiles of patients with FTD typically reveal deficits on frontal systems tasks, including verbal fluency, abstraction, and executive function. ${ }^{45}$ Using discriminant analysis, one study found that the FAS word fluency test was the instrument that best differentiated FTD from AD. ${ }^{46}$ Although it has been suggested that tests of constructional ability differ significantly between FTD and $\mathrm{AD},{ }^{43}$ this is not always the case. ${ }^{46}$ Some patients with $\mathrm{AD}$ demonstrate substantial executive deficits; ${ }^{47}$ hence neither the clinical nor neuropsychologic profile of the frontotemporal syndrome is specific for FTD. There are no clinical features that are useful for establishing either the histologic subtype of FTD or linkage to tau mutations.

Prion diseases. Until recently, diagnosis of Creutzfeldt-Jakob disease (CJD) disease rested on clinical symptoms, the characteristic electroencephalographic pattern of periodic sharp wave complexes and the pathologic examination of brain tissue. The diagnostic criteria for CJD were tested in a prospective, Class I study ${ }^{48}$ in which 188 autopsy-confirmed cases (97\%) were identified of 193 cases diagnosed with "probable" CJD based on criteria of Masters et al. ${ }^{49}$ In this same cohort, among 54 cases diagnosed with "possible" CJD, the diagnosis was confirmed in 44 (81\%). Only 2 pathologically diagnosed CJD cases were found among 111 patients who had been given other clinical diagnoses. Brown et al. ${ }^{50}$ proposed a simplified diagnostic scheme that has not been subjected to prospective study but is very similar to that used by Poser et al. ${ }^{48}$

Conclusions. The criteria of probable AD has good sensitivity for neuropathologic AD but less optimal specificity. The clinical phenotypes embodied in the diagnostic criteria for VAD, DLB, and FTD do not map precisely onto neuropathologic phenotypes. Although there are strong clinical-pathologic relationships for these disorders in the majority of patients, there are many patients with atypical or nonspecific clinical presentations. The clinical phenotype of CJD is more tightly linked to its expected CJD pathology.

\section{Practice recommendations.}

- The NINCDS-ADRDA for the diagnosis of probable AD or DSM-IIIR criteria for DAT should be routinely used (Guideline).

- The Hachinski Ischemic Index criteria may be of use in the diagnosis of cerebrovascular disease in dementia (Option).

- The Consortium for DLB diagnostic criteria may be of use in clinical practice (Option).

- The Consensus diagnostic criteria for FTD may be of use in clinical practice (Option).

- Clinical criteria for CJD should be used in rapidly progressive dementia syndromes (Guideline).

Do laboratory tests improve the accuracy of clinical diagnosis of dementing illness?

Structural neuroimaging for differential diagnosis. Since the previous practice parameter on dementia, ${ }^{1}$ one additional Class II study ${ }^{51}$ has addressed structural imaging in the diagnostic evaluation of patients with dementia. The study ${ }^{51}$ found that $5 \%$ of patients had a clinically significant structural lesion but no features in the history or examination that would have predicted the lesions. Other Class II studies that have examined the decision to order a brain imaging study on clinical history and examination alone have shown imperfect precision, although specificity and sensitivity may be approximately $90 \%{ }^{52,53}$ Given the goal of minimal undetected structural lesions, the data supports the use of a neuroimaging examination - either a noncontrast CT or MR scan - under most circumstances at the time of the initial dementia assessment to identify pathology such as brain neoplasms or subdural hematomas. A third condition, normal pressure hydrocephalus, which might be detected by CT or MR and might be responsive to treatment is very rare. ${ }^{54}$ 
Quantitative imaging to diagnose AD. Only one prospective (Class I) study of quantitative computed tomographic imaging was found that used autopsy-confirmed diagnosis as the diagnostic standard. ${ }^{55}$ Among 86 autopsied cases, a minimum width of the medial temporal lobe falling below the 5th percentile was $95 \%$ sensitive but only $40 \%$ specific for $\mathrm{AD}$.

Several Class II studies without neuropathologic confirmation of the diagnosis have reported the utility of medial temporal lobe atrophy, particularly hippocampal or entorhinal atrophy, for the clinical diagnosis of $\mathrm{AD}^{56,57} \mathrm{In}$ differentiating clinically diagnosed AD (NINCDS-ADRDA criteria) from elderly normal controls, the sensitivity of various medial temporal atrophy measures on $\mathrm{CT}^{58}$ or $\mathrm{MRI}^{59-62}$ ranged from 77 to $92 \%$, with specificities ranging from 49 to $95 \%$. Automated volumetric techniques with MRI were most reliable but are currently labor-intensive and not widely available. There are no studies that have determined the added value of measurements of hippocampal or entorhinal volume once a clinical diagnosis of $\mathrm{AD}$ has been made. The range of estimates suggests that measurement of hippocampal atrophy by MRI may not be useful in clinical practice because of its low precision.

Combining medial temporal measures with other potentially informative markers, such as functional neuroimaging ${ }^{58}$ or apolipoprotein E genotyping, may improve diagnostic accuracy. ${ }^{63}$ Determination of the rate of change of hippocampal atrophy ${ }^{64}$ may also be of value diagnostically but is unlikely to be of use in clinical practice. Prediction of subsequent AD in individuals without dementia has also been attempted with MRI of the hippocampus and entorhinal cortex ${ }^{65,66}$ but that is beyond the scope of this parameter.

Functional neuroimaging. SPECT and AD. Based on Class II studies, the sensitivity of SPECT was lower than that of the clinical diagnosis. ${ }^{58,67}$ In a single prospective study, when specificity was set at $89 \%$ overall sensitivity was $43 \%{ }^{67}$ Sensitivity increased as the severity of dementia worsened, but the pretest probability of AD also became higher. ${ }^{68,69}$ The added value of SPECT was greatest for a positive test among patients with mild dementia in whom there was substantial doubt about the diagnosis of $\mathrm{AD}$ (e.g., prior probability between 30 and 50\%). ${ }^{68}$ In this situation, a positive SPECT would have increased the posttest probability of $\mathrm{AD}$ by $30 \%$, whereas a negative test result would have increased the likelihood of no AD by only $10 \%$. Higher sensitivity ( 77 to $86 \%$ ) and specificity ( 90 to $94 \%$ ) have been reported using automated and quantitative methods for SPECT analysis. ${ }^{70,71}$

To assess the value of SPECT in the differential diagnosis of dementia, we identified two SPECT studies (Class I) with autopsy-confirmed diagnoses in a large number of subjects. ${ }^{55,72}$ For the differentiation of AD versus non-AD dementia, hypoperfusion in the temporal-parietal lobe(s) was reported to be 86 to $95 \%$ sensitive and 42 to $73 \%$ specific. Although encouraging, these figures are not consistently better than those obtained by diagnosis with established clinical criteria.

PET and AD. The largest series of dementia cases who underwent PET scans and also had autopsy confirmation was reported in a Class II study ${ }^{73}$ that included 22 patients with various types of dementia $(64 \% \mathrm{AD})$. In this study, visual interpretations of PET scans, which have high interrater reliability ${ }^{74}$ yielded a sensitivity of $93 \%$ and a specificity of $63 \%$.

A direct comparison (Class II) of FDG-PET and HMPAO-SPECT in their ability to differentiate AD from vascular dementia indicated higher diagnostic accuracy for PET regardless of dementia severity. ${ }^{75}$ Using receiver-operator characteristic curves, SPECT diagnostic accuracy was $62.9 \%$ for Mini-Mental State Examination (MMSE) score $>20$ and $81.2 \%$ for MMSE score $<20$. For PET, diagnostic accuracy was $87.2 \%$ for MMSE score $>20$ and $100 \%$ for MMSE score $<20$. Other Class II studies confirmed a lower sensitivity for high-resolution SPECT compared with PET. ${ }^{76}$ FDG-PET appears superior to MRI measures of hippocampal atrophy because changes in cerebral glucose metabolism antedate the onset of memory decline whereas the MRI hippocampal changes do not. ${ }^{77}$

PET scanning appears to have promise for use as an adjunct to clinical diagnosis, but further prospective studies with PET are needed to establish the value that it brings to diagnosis over and above a competent clinical diagnosis.

SPECT, PET, and FTD. SPECT and PET may be helpful in distinguishing FTD from AD. Many patients with FTD show hypoperfusion of anterior cerebral cortex with relative sparing of posterior cortex with SPECT ${ }^{78-80}$ and PET. ${ }^{81}$ In these four Class II studies, the highly selected study participant pool makes it difficult to generalize on the reported specificities and sensitivities. In patients with cognitive or behavioral deficits suggestive of FTD, no studies addressed what additional value a SPECT or PET scan provides.

Genetic biomarkers. No studies have addressed the value of genetic counseling for patients with dementia or their families when autosomal dominant disease is suspected. Because the genetics of dementing illnesses is a very young field, expertise in genetic counseling for the dementias of the elderly is likely to be found only in specialized dementia research centers. Advances in the identification of genetic markers for AD and other dementias have raised awareness of the familial nature of the dementias, even when autosomal dominant transmission is not evident.

$\mathrm{AD}$ and genetic risks. In a large neuropathologically confirmed cohort of patients with dementia, the use of apolipoprotein E4 slightly increased the positive predictive value of the AD diagnosis (Class II). ${ }^{18}$ These authors showed that relative to the neuropathologic diagnosis of $\mathrm{AD}$, the sensitivity of the clinical diagnosis of $\mathrm{AD}$ was $92 \%$, whereas sensitivity of having at least one APOE E4 allele was only $65 \%$. However, in patients with clinical diagnoses of AD, the addition of APOE testing increased the positive predictive value (using the prevalence of AD in this dementia autopsy series) of a diagnosis of AD by approximately 4\% (from 90 to 94\%) if an APOE E4 allele was present. In patients with a 
clinical diagnosis of non-AD, the absence of an APOE E4 allele increased the negative predictive value by $8 \%$ (from 64 to $72 \%$ ).

FTD and genetic risks. A relatively high prevalence of tau mutations was found in a Dutch population (17.8\% of all FTD cases and $40.3 \%$ of all familial FTD cases). ${ }^{82}$ In contrast, no tau mutations were found in a large U.S. clinical nonAD dementia sample. ${ }^{83}$ The yield of diagnostic and prognostic information from screening of sporadic cases of suspected FTD for the known mutations of the tau gene is likely to be very low.

DLB and genetic risks. There are no clinically relevant associations between any genetic markers and DLB.

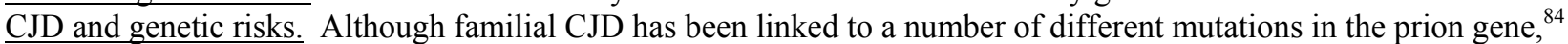
and a polymorphism at one codon has been shown to be more common in sporadic $\mathrm{CJD},{ }^{85,86}$ there is no evidence currently that genetic analysis of the prion gene is of value in the diagnosis of suspected CJD.

CSF markers. Since the publication of the previous practice parameter, we encountered no new published studies that addressed the issue of routine versus selective CSF analysis in the evaluation of a patient with dementia. However, since 1994, there has been intense interest in developing markers related to the neuropathology of AD in CSF.

CSF $ß$-amyloid $_{1-42}$ : Reduced levels of $\beta$-amyloid - $_{1-42}$ in CSF of patients with AD compared with normal elderly controls have been observed repeatedly in Class II and III studies. ${ }^{87-90}$ Using post-hoc cut-points, moderate sensitivities ( 78 to $92 \%$ ) and specificities ( 81 to $83 \%$ ) have been achieved in distinguishing patients with AD from normal elderly controls. ${ }^{87-89}$ It is unclear whether CSF levels of $\beta$-amyloid -am $_{-42}$ retain diagnostic usefulness in patients with very mild AD. ${ }^{91}$

CSF tau. CSF tau level was shown to be significantly elevated in patients with AD compared with normal controls in Class II and III studies. ${ }^{92-95}$ CSF tau distinguished AD from normal controls with 80 to $97 \%$ sensitivity and 86 to $95 \%$ specificity. However, elevated CSF tau level has also been detected in patients with other neurodegenerative diseases. ${ }^{92}$ CSF tau levels may be useful in supporting a diagnosis of AD early in the course of dementia. ${ }^{93,95}$ Although sensitivity and specificity of CSF tau measurements appear very good, there are no studies that determine the benefits of CSF tau over a good clinical diagnosis.

CSF $\beta$-amyloid ${ }_{1-42}$ and tau. The diagnostic yield may be improved by the simultaneous measurement of CSF $\beta-$ amyloid $_{1-42}$ and tau. In Class II and III studies, sensitivities of $85 \%$ and specificities of $87 \%$ have been reported. $^{88-90}$ Additional studies are needed to establish the value that the combined use of these markers brings to diagnosis over and above a competent clinical diagnosis.

CSF AD7C-NTP. Although specificities of 89 and 94\% have been cited for CSF AD7C protein in early AD and possible or probable AD versus demented controls, patient selection and characterization in the studies ${ }^{96-98}$ lacked scientific rigor. A recent Class II study with better methodology ${ }^{99}$ showed that CSF AD7C-NTP had a specificity of $87 \%$ and a sensitivity of $70 \%$.

CSF 14-3-3 protein and neuron-specific enolase. An immunoassay for the detection of the 14-3-3 protein in CSF has been described ${ }^{100}$ that had a specificity of $99 \%$ and a sensitivity of $96 \%$ for the diagnosis of CJD among patients with dementia who had not had a stroke within one month of testing. A large German national surveillance study (Class I) of CJD also reported a sensitivity of $94 \%$, specificity of $93 \%$, and positive predictive value of $95 \%$ for $14-3-3$ CSF assay. ${ }^{101}$ In this same population, the CSF 14-3-3 protein assay was superior to EEG or MR in identifying cases of CJD. ${ }^{48}$ However, other acute neurologic conditions such as stroke, viral encephalitis, and paraneoplastic neurologic disorders can provide false positive results. ${ }^{100-103}$ A negative 14-3-3 immunoassay does not rule out CJD. ${ }^{104}$ The additional use of neuron-specific enolase does not appear to substantially improve diagnostic accuracy. ${ }^{105}$

Other biomarkers. No other biomarkers that had been extensively studied and had promising detection abilities for $\mathrm{AD}$ or other dementias were uncovered in the literature search.

Conclusions. The CSF 14-3-3 protein assay is useful for confirming the diagnosis of CJD. In contrast, no laboratory tests have yet emerged that are appropriate for routine use in the clinical evaluation of patients with suspected AD. Several promising avenues - genotyping, imaging and biomarkers - are being pursued, but proof that a laboratory test has value is arduous. Ultimately, the putative diagnostic test must be administered to a representative sample of patients with dementia who eventually have pathologic confirmation of their diagnoses. A valuable test will be one that increases diagnostic accuracy over and above a competent clinical diagnosis.

\section{Practice recommendations.}

- Structural neuroimaging with either a noncontrast CT or MR scan in the routine initial evaluation of patients with dementia is appropriate (Guideline).

- Linear or volumetric MR or CT measurement strategies for the diagnosis of AD and are not recommended for routine use at this time (Guideline).

- For patients with suspected dementia, SPECT cannot be recommended for routine use in either initial or differential diagnosis as it has not demonstrated superiority to clinical criteria (Guideline).

- $\quad$ PET imaging is not recommended for routine use in the diagnostic evaluation of dementia at this time (Guideline). 
- Genetic testing of patients with suspected DLB and CJD is not recommended (Guideline).

- Routine use of APOE genotyping in patients with suspected AD is not recommended at this time (Guideline).

- There are no other genetic markers recommended for routine use in the diagnosis of AD (Guideline).

- Testing for tau mutations or AD gene mutations is not recommended for routine evaluation in patients with FTD at this time (Guideline).

- There are no CSF or other biomarkers recommended for routine use in determining the diagnosis of $\mathrm{AD}$ at this time (Guideline).

- The CSF 14-3-3 protein is recommended for confirming or rejecting the diagnosis of CJD in clinically appropriate circumstances (Guideline).

What comorbidities should be screened for in elderly patients undergoing an initial assessment for dementia? The prior Practice parameter ${ }^{1}$ recommended a number of laboratory tests (including complete blood count, serum electrolytes, glucose, blood urea nitrogen/creatinine, folate, $\mathrm{B}_{12}$, thyroid function, and syphilis serology) as routine assessment in patients undergoing assessment for dementia. Since that time, no studies were identified that evaluated these recommendations. However, since 1994, several studies have been published that specifically addressed the diagnostic value of vitamin $B_{12}$ levels, thyroid function analysis, and syphilis screening. No studies were identified that addressed the utility of such tests as 24-hour urine collection for heavy metals or serum toxicology screens.

Depression. Prospective studies show that individuals with depression and coexistent cognitive impairment are highly likely to have an underlying dementia on longitudinal follow-up. ${ }^{106-111} \mathrm{In}$ one of the studies, ${ }^{110}$ nearly $12 \%$ of patients with dementia were also depressed. Validated instruments for screening for depression exist, such as the Geriatric Depression Scale, short form, ${ }^{112}$ the Centers for Epidemiologic Studies Depression scale, ${ }^{113}$ and the Hamilton Depression Scale. ${ }^{114}$

Vitamin $B_{12}$. Vitamin $\mathrm{B}_{12}$ deficiency is common in the elderly. ${ }^{115}$ Reports of improvement in cognitively impaired individuals with $B_{12}$ deficiency are equivocal. ${ }^{116-119}$ Patients with $B_{12}$ deficiency have had slightly lower cognitive performance than nondeficient subjects, ${ }^{120}$ but low vitamin $B_{12}$ levels in nondemented subjects carried no risk for the subsequent development of dementia. ${ }^{121}$ The number of patients with dementia caused by $\mathrm{B}_{12}$ deficiency states has been very small in prevalence studies ${ }^{122}$ or meta-analyses of clinic samples. ${ }^{123,124}$ Diagnostic algorithms for refined diagnoses of vitamin $\mathrm{B}_{12}$ deficiencies have been published. ${ }^{125}$

Thyroid functions. Hypothyroidism is common in the elderly. ${ }^{126-128}$ Nondemented patients with hypothyroidism had lower mental status test scores, word fluency, visuospatial abilities, and learning than euthyroid controls, ${ }^{129}$ but two other studies $^{128,130}$ found no relationship between TSH and cognitive function. The vast majority of patients with clinically significant hypothyroidism in these studies ${ }^{128-130}$ lacked dementia. On the other hand, elevated TSH levels carried an increased risk for dementia in a population-based study. ${ }^{131}$ In dementia prevalence studies ${ }^{122}$ and clinic sample metaanalyses, ${ }^{123,132}$ there were only a very small number of patients with dementia attributable to hypothyroidism, which was either partially or completely reversed with treatment of hypothyroidism.

Other common metabolic abnormalities possibly associated with dementia. Other metabolic disturbances are also sometimes included in the differential diagnosis of dementia. In the series of Clarfield ${ }^{123}$ and Weytingh, ${ }^{124}$ hypoparathyroidism and hepatic encephalopathy were mentioned as illnesses that with treatment resulted in complete resolution of dementia.

Tests for syphilis. There are only a few areas in the United States, mainly in the southern tier of the country and in some regions of the Midwest, with high numbers of syphilis cases. ${ }^{133}$ Thirty-one U.S. counties account for $50 \%$ of all reported cases of primary and secondary syphilis. ${ }^{133}$ Within the last 20 years, there have been no reported cases of tertiary syphilis in any of the incidence ${ }^{134-138}$ or prevalence ${ }^{122,135,139-145}$ studies conducted in North America. Except in these highincidence regions, screening for the disorder in patients with dementia without an increased pretest probability would appear to be ill-supported because positive serum Venereal Disease Research Laboratory, rapid plasma reagin, and fluorescent treponemal antibody tests are nonspecific. ${ }^{146,147}$

Conclusions. Depression, $\mathrm{B}_{12}$ deficiency, and hypothyroidism are comorbidities that are likely to appear in the elderly and in patients with suspected dementia in particular. Although treatment of these disorders may not completely reverse cognitive dysfunction, they should be recognized and treated. No new evidence has appeared since 1994 to support or refute the recommendation to perform "routine" blood tests in patients being evaluated for dementia.

\section{Practice recommendations.}

- Depression is a common, treatable comorbidity in patients with dementia and should be screened for (Guideline).

- $\mathrm{B}_{12}$ deficiency is common in the elderly, and $\mathrm{B}_{12}$ levels should be included in routine assessments of the elderly (Guideline).

- Because of its frequency, hypothyroidism should be screened for in elderly patients (Guideline). 
- Unless the patient has some specific risk factor or evidence of prior syphilitic infection, or resides in one of the few areas in the United States with high numbers of syphilis cases, screening for the disorder in patients with dementia is not justified (Guideline).

Recommendations for future research. Although the DSM-IIIR definitions of dementia are reliable, clarification of the cognitive domains of dementia in the definitions would allow diseases such as some forms of VAD, as well as DLB and FTD, to be better integrated. Memory disorders are not necessarily part of the initial presentation of these disorders. Therefore, memory disorder should not be a required part of the definition of dementia. In addition, the definitions of the specific, common diseases that cause dementia-AD, VAD, DLB, and FTD — should be refined to minimize incompatibilities and confusing overlap between categories. Explicit recognition of the pathologic overlap of $\mathrm{AD}, \mathrm{VAD}$, and DLB in the diagnostic criteria might lead to a more realistic approach to clinical diagnosis. Further work must be done to improve the precision of the diagnoses of VAD and DLB in particular. The diagnosis of mild cognitive impairment (see Practice Parameter on Early Detection of Dementia) also should be integrated with the definition of dementia as well as the definitions of specific diseases. As we move into an era of earlier recognition of cognitive impairment, clarification of the distinctions between no cognitive impairment, mild cognitive impairment, and early dementia is needed.

Biomarkers for $\mathrm{AD}$ and other dementias are critically needed, and the validation of these markers will require crosssectional studies and longitudinal, population-based studies with diagnosis confirmation at autopsy. If a goal of therapy for patients with dementia is to intervene before the disease has diminished cognitive function, imaging techniques or biomarkers must be capable of detecting $\mathrm{AD}$ pathology in asymptomatic individuals. The same consideration applies to DLB and FTD pathology. Even if a biomarker does not substantially enhance diagnostic precision in symptomatic patients, a biomarker with high sensitivity and specificity for a particular dementing disorder in symptomatic patients is one that could be of use in presymptomatic detection. The genomic identification of specific dementias and risk of their development offer prospects for future research.

Disclaimer. This statement is provided as an educational service of the American Academy of Neurology. It is based on an assessment of current scientific and clinical information. It is not intended to include all possible proper methods of care for a particular neurologic problem or all legitimate criteria for choosing to use specific procedures. Neither is it intended to exclude any reasonable alternative methodologies. The AAN recognizes that specific patient care decisions are the prerogative of the patient and the physician caring for the patient, based on all the circumstances involved.

\section{Acknowledgment}

The Dementia Diagnosis Committee would like to thank Ms. Wendy Edlund and Ms. Alison Nakashima of the AAN for their support of this project; James Stevens, MD, of the QSS Committee of the AAN for his enthusiasm for the project and his guidance through the evidence-based approach; Ms. Vicki Glasgow of the University of Minnesota Biomedical Library for her assistance in the literature searches; and Starr Pearlman, $\mathrm{PhD}$, for her assistance in editing and compiling the final versions of this document.

\section{Appendix}

Quality Standards Subcommittee Members: Gary Franklin, MD, MPH, Co-Chair; Catherine Zahn, MD, Co-Chair; Milton Alter, MD, PhD; Stephen Ashwal, MD; John Calverley, MD; Richard M. Dubinsky, MD; Jacqueline French, MD; Michael Glantz, MD; Gary Gronseth, MD; Deborah Hirtz, MD; Robert G. Miller, MD; James C. Stevens, MD, Facilitator; and William J. Weiner, MD.

\section{References}

1. Practice parameter for diagnosis and evaluation of dementia. (summary statement). Report of the Quality Standards Subcommittee of the American Academy of Neurology. Neurology 1994; 44: 2203-2206.

2. McKhann G, Drachman D, Folstein M, et al. Clinical diagnosis of Alzheimer's disease: report of the NINCDS-ADRDA Work Group under the auspices of Department of Health and Human Services Task Force on Alzheimer's Disease. Neurology 1984; 34: 939-944.

3. American Psychiatric Association. Diagnostic and Statistical Manual of Mental Disorders, 3rd edition, revised. Washington, D.C.: American Psychiatric Association, 1987.

4. American Psychiatric Association. Diagnostic and Statistical Manual of Mental Disorders. 4th ed. Washington, D.C.: American Psychiatric Association, 1994.

5. Graham JE, Rockwood K, Beattie BL, et al. Standardization of the diagnosis of dementia in the Canadian Study of Health and Aging. Neuroepidemiology 1996; 15: 246-256.

6. Larson EB, McCurry SM, Graves AB, et al. Standardization of the clinical diagnosis of the dementia syndrome and its subtypes in a cross-sectional study: the Ni-Hon-Sea experience. J Gerontol A Biol Sci Med Sci 1998; 53A: M313-M319.

7. Fratiglioni L, Grut M, Forsell Y, et al. Clinical diagnosis of Alzheimer's disease and other dementias in a population survey. Agreement and causes of disagreement in applying Diagnostic and Statistical Manual of Mental Disorders, Revised Third Edition, Criteria. Arch Neurol 1992; 49: 927-932.

8. Farrer LA, Cupples LA, Blackburn S, et al. Interrater agreement for diagnosis of Alzheimer's disease: the MIRAGE study. Neurology 1994; 44: 652-656.

9. Blacker D, Albert MS, Bassett SS, et al. Reliability and validity of NINCDS-ADRDA criteria for Alzheimer's disease. The National Institute of Mental Health Genetics Initiative. Arch Neurol 1994; 51: 1198-1204. 
10. Lopez OL, Litvan I, Catt KE, et al. Accuracy of four clinical diagnostic criteria for the diagnosis of neurodegenerative dementias. Neurology 1999; 53: 1292-1299.

11. Forette F, Henry JF, Orgogozo JM, et al. Reliability of clinical criteria for the diagnosis of dementia. A longitudinal multicenter study. Arch Neurol 1989; 46: 646-648.

12. Holmes C, Cairns N, Lantos $\mathrm{P}$, et al. Validity of current clinical criteria for Alzheimer's disease, vascular dementia and dementia with Lewy bodies. Br J Psychiatry 1999; 174: 45-50.

13. Jobst KA, Barnetson LP, Shepstone BJ. Accurate prediction of histologically confirmed Alzheimer's disease and the differential diagnosis of dementia: the use of NINCDS-ADRDA and DSM- III-R criteria, spect, X-ray CT, and apo E4 in medial temporal lobe dementias. Oxford Project to Investigate Memory and Aging. Int Psychogeriatr 1998; 10: 271-302.

14. Lim A, Tsuang D, Kukull W, et al. Clinico-neuropathological correlation of Alzheimer's disease in a community-based case series. J Am Geriatr Soc 1999; 47: 564-569.

15. Wade JP, Mirsen TR, Hachinski VC, et al. The clinical diagnosis of Alzheimer's disease. Arch Neurol 1987; 44: $24-29$.

16. Victoroff J, Mack WJ, Lyness SA, et al. Multicenter clinicopathological correlation in dementia. Am J Psychiatry 1995; 152: 14761484.

17. Galasko D, Hansen LA, Katzman R, et al. Clinical-neuropathological correlations in Alzheimer's disease and related dementias. Arch Neurol 1994; 51: 888-895.

18. Mayeux R, Saunders AM, Shea S, et al. Utility of the apolipoprotein E genotype in the diagnosis of Alzheimer's disease. Alzheimer's Disease Centers Consortium on Apolipoprotein E and Alzheimer's Disease. N Engl J Med 1998; 338: 506-511.

19. Klatka LA, Schiffer RB, Powers JM, et al. Incorrect diagnosis of Alzheimer's disease. A clinicopathologic study. Arch Neurol 1997; 53: $35-42$.

20. Gearing M, Mirra SS, Hedreen JC, et al. The Consortium to Establish a Registry for Alzheimer's Disease (CERAD). Part X. Neuropathology confirmation of the clinical diagnosis of Alzheimer's disease. Neurology 1995; 45: 461-466.

21. Berg L, McKeel DW Jr., Miller JP, et al. Clinicopathologic studies in cognitively healthy aging and Alzheimer's disease: relation of histologic markers to dementia severity, age, sex, and apolipoprotein E genotype. Arch Neurol 1998; 55: 326-335.

22. Massoud F, Devi G, Stern Y, et al. A clinicopathological comparison of community-based and clinic-based cohorts of patients with dementia. Arch Neurol 1999; 56: 1368-1373.

23. Chui HC, Victoroff JI, Margolin D, et al. Criteria for the diagnosis of ischemic vascular dementia proposed by the State of California Alzheimer's Disease Diagnostic and Treatment Centers. Neurology 1992; 42: 473-480.

24. Roman GC, Tatemichi TK, Erkinjuntti T, et al. Vascular dementia: diagnostic criteria for research studies. Report of the NINDSAIREN International Workshop. Neurology 1993; 43: 250-260.

25. Hachinski VC, Lassen NA, Marshall J. Multi-infarct dementia. A cause of mental deterioration in the elderly. Lancet 1974; 2: 207210.

26. Rosen WG, Terry RD, Fuld PA, et al. Pathological verification of ischemic score in differentiation of dementias. Ann Neurol 1980; 7: 486-488.

27. Moroney JT, Bagiella E, Desmond DW, et al. Meta-analysis of the Hachinski Ischemic Score in pathologically verified dementias. Neurology 1997; 49: 1096-1105.

28. Gold G, Giannakopoulos P, Montes-Paixao Junior C, et al. Sensitivity and specificity of newly proposed clinical criteria for possible vascular dementia. Neurology 1997; 49: 690-694.

29. McKeith IG, Galasko D, Kosaka K, et al. Consensus guidelines for the clinical and pathologic diagnosis of dementia with Lewy bodies (DLB): report of the consortium on DLB international workshop. Neurology 1996; 47: 1113-1124.

30. Litvan I, MacIntyre A, Goetz CG, et al. Accuracy of the clinical diagnoses of Lewy body disease, Parkinson disease, and dementia with Lewy bodies: a clinicopathologic study. Arch Neurol 1998; 55: 969-978.

31. Luis CA, Barker WW, Gajaraj K, et al. Sensitivity and specificity of three clinical criteria for dementia with Lewy bodies in an autopsy-verified sample. Int J Geriatr Psychiatry 1999; 14: 526-533.

32. Mega MS, Masterman DL, Benson DF, et al. Dementia with Lewy bodies: reliability and validity of clinical and pathologic criteria. Neurology 1996; 47: 1403-1409.

33. Verghese J, Crystal HA, Dickson DW, et al. Validity of clinical criteria for the diagnosis of dementia with Lewy bodies. Neurology 1999; 53: 1974-1982.

34. Ballard C, Holmes C, McKeith I, et al. Psychiatric morbidity in dementia with Lewy bodies: a prospective clinical and neuropathological comparative study with Alzheimer's disease. Am J Psychiatry 1999; 156: 1039-1045.

35. Hohl U, Tiraboschi P, Hansen LA, et al. Diagnostic accuracy of dementia with Lewy bodies. Arch Neurol 2000; 57: 347-351.

36. Heyman A, Fillenbaum GG, Gearing M, et al. Comparison of Lewy body variant of Alzheimer's disease with pure Alzheimer's disease: Consortium to Establish a Registry for Alzheimer's Disease, Part XIX. Neurology 1999; 52: 1839-1844.

37. Ballard CG, Ayre G, O'Brien J, et al. Simple standardised neuropsychological assessments aid in the differential diagnosis of dementia with Lewy bodies from Alzheimer's disease and vascular dementia. Dement Geriatr Cogn Disord 1999; 10 : $104-108$.

38. Barber R, Gholkar A, Scheltens P, et al. Medial temporal lobe atrophy on MRI in dementia with Lewy bodies. Neurology 1999; 52: $1153-1158$.

39. Ishii K, Imamura T, Sasaki M, et al. Regional cerebral glucose metabolism in dementia with Lewy bodies and Alzheimer's disease. Neurology 1998; 51: 125-130.

40. Brun A. Frontal lobe degeneration of non-Alzheimer type revisited. Dementia 1993; 4: 126-131.

41. Varma AR, Snowden JS, Lloyd JJ, et al. Evaluation of the NINCDS-ADRDA criteria in the differentiation of Alzheimer's disease and frontotemporal dementia. J Neurol Neurosurg Psychiatry 1999; 66: 184-188.

42. Miller BL, Ikonte C, Ponton M, et al. A study of the Lund-Manchester research criteria for frontotemporal dementia: clinical and single-photon emission CT correlations. Neurology 1997; 48: 937-942.

43. Clinical and neuropathological criteria for frontotemporal dementia. The Lund and Manchester Groups. J Neurol Neurosurg Psychiatry 1994; 57: 416-418. 
44. Neary D, Snowden JS, Gustafson L, et al. Frontotemporal lobar degeneration: a consensus on clinical diagnostic criteria. Neurology 1998; 51: 1546-1554.

45. Miller BL, Cummings JL, Villanueva-Meyer J, et al. Frontal lobe degeneration: clinical, neuropsychological, and SPECT characteristics. Neurology 1991; 41: 1374-1382.

46. Lindau M, Almkvist O, Johansson SE, et al. Cognitive and behavioral differentiation of frontal lobe degeneration of the nonAlzheimer type and Alzheimer's disease. Dement Geriatr Cogn Disord 1998; 9: 205-213.

47. Johnson JK, Head E, Kim R, et al. Clinical and pathological evidence for a frontal variant of Alzheimer disease. Arch Neurol 1999; 56: $1233-1239$.

48. Poser S, Mollenhauer B, Kraubeta A, et al. How to improve the clinical diagnosis of Creutzfeldt-Jakob disease. Brain 1999; 122: 2345-2351.

49. Masters CL, Harris JO, Gajdusek DC, et al. Creutzfeldt-Jakob disease: patterns of worldwide occurrence and the significance of familial and sporadic clustering. Ann Neurol 1979; 5: 177-188.

50. Brown P, Cathala F, Castaigne P, et al. Creutzfeldt-Jakob disease: clinical analysis of a consecutive series of 230 neuropathologically verified cases. Ann Neurol 1986; 20: 597-602.

51. Chui H, Zhang Q. Evaluation of dementia: a systematic study of the usefulness of the American Academy of Neurology's practice parameters. Neurology 1997; 49: 925-935.

52. Alexander EM, Wagner EH, Buchner DM, et al. Do surgical brain lesions present as isolated dementia? A population-based study. J Am Geriatr Soc 1995; 43: 138-143.

53. Martin DC, Miller J, Kapoor W, et al. Clinical prediction rules for computed tomographic scanning in senile dementia. Arch Intern Med 1987; 147: 77-80.

54. Vanneste J, Augustijn P, Dirven C, et al. Shunting normal-pressure hydrocephalus: do the benefits outweigh the risks? A multicenter study and literature review. Neurology 1992; 42: 54-59.

55. Nagy Z, Hindley NJ, Braak H, et al. Relationship between clinical and radiological diagnostic criteria for Alzheimer's disease and the extent of neuropathology as reflected by "stages": a prospective study. Dement Geriatr Cogn Disord 1999; 10: $109-114$.

56. De Leon MJ, George AE, Golomb J, et al. Frequency of hippocampal formation atrophy in normal aging and Alzheimer's disease. Neurobiol Aging 1997; 18: 1-11.

57. Xu Y, Jack CR Jr., O’Brien PC, et al. Usefulness of MRI measures of entorhinal cortex versus hippocampus in AD. Neurology 2000; 54: $1760-177$.

58. Mattman A, Feldman H, Forster B, et al. Regional HmPAO SPECT and CT measurements in the diagnosis of Alzheimer's disease. Can J Neurol Sci 1997; 24: 22-28.

59. Laakso MP, Soininen H, Partanen K, et al. MRI of the hippocampus in Alzheimer's disease: sensitivity, specificity, and analysis of the incorrectly classified subjects. Neurobiol Aging 1998; 19: 23-31.

60. Pucci E, Belardinelli N, Regnicolo L, et al. Hippocampus and parahippocampal gyrus linear measurements based on magnetic resonance in Alzheimer's disease. Eur Neurol 1998; 39: 16-25.

61. Jack CR Jr., Petersen RC, Xu YC, et al. Medial temporal atrophy on MRI in normal aging and very mild Alzheimer's disease. Neurology 1997; 49: 786-794.

62. O'Brien JT, Desmond P, Ames D, Schweitzer I, Chiu E, Tress B. Temporal lobe magnetic resonance imaging can differentiate Alzheimer's disease from normal aging, depression, vascular dementia and other causes of cognitive impairment. Psychol Med 1997; 27: $1267-1275$.

63. Jack CR Jr., Petersen RC, Xu YC, et al. Hippocampal atrophy and apolipoprotein E genotype are independently associated with Alzheimer's disease. Ann Neurol 1998; 43: 303-310.

64. Smith AD, Jobst KA. Use of structural imaging to study the progression of Alzheimer's disease. Br Med Bull 1996; 52: 575-586.

65. Killiany RJ, Gomez-Isla T, Moss M, et al. Use of structural magnetic resonance imaging to predict who will get Alzheimer's disease. Ann Neurol 2000; 47: 430-439.

66. Jack CR, Petersen RC, Xu YC, et al. Prediction of AD with MRI-based hippocampal volume in mild cognitive impairment. Neurology 1999; 52: 1397-1403.

67. Van Gool WA, Walstra GJ, Teunisse S, et al. Diagnosing Alzheimer's disease in elderly, mildly demented patients: the impact of routine single photon emission computed tomography. J Neurol 1995; 242: 401-405.

68. Claus JJ, van Harskamp F, Breteler MM, et al. The diagnostic value of SPECT with Tc 99m HMPAO in Alzheimer's disease: a population-based study. Neurology 1994; 44: 454-461.

69. Johnson KA, Holman BL, Rosen TJ, et al. Iofetamine I 123 single photon emission computed tomography is accurate in the diagnosis of Alzheimer's disease. Arch Intern Med 1990; 150: 752-756.

70. Johnson KA, Kijewski MF, Becker JA, et al. Quantitative brain SPECT in Alzheimer's disease and normal aging. J Nucl Med 1993; 34: 2044-2048.

71. Bartenstein P, Minoshima S, Hirsch C, et al. Quantitative assessment of cerebral blood flow in patients with Alzheimer's disease by SPECT. J Nucl Med 1997; 38: 1095-1101.

72. Bonte FJ, Weiner MF, Bigio EH, et al. Brain blood flow in the dementias: SPECT with histopathologic correlation in 54 patients. Radiology 1997; 202: 793-797.

73. Hoffman JM, Welsh-Bohmer K, Hanson M, et al. FDG-PET imaging in pathologically verified dementia. J Nucl Med 2000; 41: 19201928.

74. Hoffman JM, Hanson MW, Welsh KA, et al. Interpretation variability of 18FDG-positron emission tomography studies in dementia. Invest Radiol 1996; 31: 316-322.

75. Mielke R, Heiss WD. Positron emission tomography for diagnosis of Alzheimer's disease and vascular dementia. J Neural Transm 1998; 53 (suppl): 237-250.

76. Messa C, Perani D, Lucignani G, et al. High-resolution technetium-99m-HMPAO SPECT in patients with probable Alzheimer's disease: comparison with fluorine-18-FDG PET. J Nucl Med 1994; 35: 210-216. 
77. Reiman EM, Uecker A, Caselli RJ, et al. Hippocampal volumes in cognitively normal persons at genetic risk for Alzheimer's disease. Ann Neurol 1998; 44: 288-291.

78. Pickut BA, Saerens J, Marien P, et al. Discriminative use of SPECT in frontal lobe-type dementia versus (senile) dementia of the Alzheimer's type. J Nucl Med 1997; 38: 929-934.

79. Read SL, Miller BL, Mena I, et al. SPECT in dementia: clinical and pathological correlation. J Am Geriatr Soc 1995; $43: 1243-1247$.

80. Talbot PR, Lloyd JJ, Snowden JS, et al. A clinical role for 99mTc-HMPAO SPECT in the investigation of dementia? J Neurol Neurosurg Psychiatry 1998; 64: 306-313.

81. Ishii K, Sakamoto S, Sasaki M, et al. Cerebral glucose metabolism in patients with frontotemporal dementia. J Nucl Med 1998; 39: $1875-1878$.

82. Rizzu P, Van Swieten JC, Joosse M, et al. High prevalence of mutations in the microtubule-associated protein tau in a population study of frontotemporal dementia in the Netherlands. Am J Hum Genet 1999; 64: 414-421.

83. Houlden H, Baker M, Adamson J, et al. Frequency of tau mutations in three series of non-Alzheimer's degenerative dementia. Ann Neurol 1999; 46: 243-248.

84. Prusiner SB, Hsiao KK. Human prion diseases. Ann Neurol 1994; 35: 385-395.

85. Tranchant C, Geranton L, Guiraud-Chaumeil C, et al. Basis of phenotypic variability in sporadic Creutzfeldt-Jakob disease. Neurology 1999; 52: 1244-1249.

86. Parchi P, Giese A, Capellari S, et al. Classification of sporadic Creutzfeldt-Jakob disease based on molecular and phenotypic analysis of 300 subjects. Ann Neurol 1999; 46: 224-233.

87. Andreasen N, Hesse C, Davidsson P, et al. Cerebrospinal fluid beta-amyloid(1-42) in Alzheimer disease: differences between earlyand late-onset Alzheimer disease and stability during the course of disease. Arch Neurol 1999; 56: 673-680.

88. Galasko D, Chang L, Motter R, et al. High cerebrospinal fluid tau and low amyloid beta42 levels in the clinical diagnosis of Alzheimer disease and relation to apolipoprotein E genotype. Arch Neurol 1998; 55: 937-945.

89. Hulstaert F, Blennow K, Ivanoiu A, et al. Improved discrimination of AD patients using beta-amyloid(1-42) and tau levels in CSF. Neurology 1999; 52: 1555-1562.

90. Shoji M, Matsubara E, Kanai M, et al. Combination assay of CSF tau, A beta 1-40 and A beta 1-42(43) as a biochemical marker of Alzheimer's disease. J Neurol Sci 1998; 158: 134-140.

91. Jensen M, Schroder J, Blomberg M, et al. Cerebrospinal fluid A beta42 is increased early in sporadic Alzheimer's disease and declines with disease progression. Ann Neurol 1999; 45: 504-511.

92. Arai H, Higuchi S, Saskai H, et al. Genotyping and cerebrospinal fluid tau protein: implications for the clinical diagnosis of Alzheimer's disease. Gerontology 1997; 43 (suppl 1): 2-10.

93. Galasko D, Clark C, Chang L, et al. Assessment of CSF levels of tau protein in mildly demented patients with Alzheimer's disease. Neurology 1997; 48: 632-635.

94. Kurz A, Riemenschneider M, Buch K, et al. Tau protein in cerebrospinal fluid is significantly increased at the earliest clinical stage of Alzheimer disease. Alzheimer Dis Assoc Disord 1998; 12: 372-377.

95. Andreasen N, Minthon L, Clarberg A, et al. Sensitivity, specificity, and stability of CSF-tau in AD in a community-based patient sample. Neurology 1999; 53: 1488-1494.

96. Ghanbari K, Ghanbari HA. A sandwich enzyme immunoassay for measuring AD7C-NTP as an Alzheimer's disease marker: AD7C test. J Clin Lab Anal 1998; 12: 223-226.

97. de la Monte SM, Ghanbari K, Frey WH, et al. Characterization of the AD7C-NTP cDNA expression in Alzheimer's disease and measurement of a 41-kD protein in cerebrospinal fluid. J Clin Invest 1997; 100: 3093-3104.

98. de la Monte SM, Volicer L, Hauser SL, et al. Increased levels of neuronal thread protein in cerebrospinal fluid of patients with Alzheimer's disease. Ann Neurol 1992; 32: 733-742.

99. Kahle PJ, Jakowec M, Teipel SJ, et al. Combined assessment of tau and neuronal thread protein in Alzheimer's disease CSF. Neurology 2000; 54: 1498-1504.

100. Hsich G, Kenney K, Gibbs CJ, et al. The 14-3-3 brain protein in cerebrospinal fluid as a marker for transmissible spongiform encephalopathies. N Engl J Med 1996; 335: 924-930.

101. Zerr I, Bodemer M, Gefeller O, et al. Detection of 14-3-3 protein in the cerebrospinal fluid supports the diagnosis of CreutzfeldtJakob disease. Ann Neurol 1998; 43: 32-40.

102. Rosenmann H, Meiner Z, Kahana E, et al. Detection of 14-3-3 protein in the CSF of genetic Creutzfeldt-Jakob disease. Neurology 1997; 49: 593-595.

103. Saiz A, Graus F, Dalmau J, et al. Detection of 14-3-3 brain protein in the cerebrospinal fluid of patients with paraneoplastic neurological disorders. Ann Neurol 1999; 46: 774-777.

104. Moussavian M, Potolicchio S, Jones R. The 14-3-3 brain protein and transmissible spongiform encephalopathy. N Engl J Med 1997; 336: 873-4; discussion 874-875.

105. Beaudry P, Cohen P, Brandel JP, et al. 14-3-3 protein, neuron-specific enolase, and S-100 protein in cerebrospinal fluid of patients with Creutzfeldt-Jakob disease. Dement Geriatr Cogn Disord 1999; 10: 40-46.

106. Visser PJ, Verhey FR, Ponds RW, et al. Distinction between preclinical Alzheimer's disease and depression. J Am Geriatr Soc 2000; 48: 479-484.

107. Alexopoulos GS, Meyers BS, Young RC, et al. The course of geriatric depression with "reversible dementia": a controlled study. Am J Psychiatry 1993; 150: 1693-1699.

108. Burt DB, Zembar MJ, Niederehe G. Depression and memory impairment: a meta-analysis of the association, its pattern, and specificity. Psychol Bull 1995; 117: 285-305.

109. Schofield PW, Marder K, Dooneief G, et al. Association of subjective memory complaints with subsequent cognitive decline in community-dwelling elderly individuals with baseline cognitive impairment. Am J Psychiatry 1997; 154: 609-615.

110. Forsell Y, Winblad B. Major depression in a population of demented and nondemented older people: prevalence and correlates. J Am Geriatr Soc 1998; 46: 27-30. 
111. Reding M, Haycox J, Blass J. Depression in patients referred to a dementia clinic. A three-year prospective study. Arch Neurol 1985; 42: 894-896.

112. Burke WJ, Roccaforte WH, Wengel SP. The short form of the Geriatric Depression Scale: a comparison with the 30-item form. J Geriatr Psychiatry Neurol 1991; 4: 173-178.

113. Andresen EM, Malmgren JA, Carter WB, et al. Screening for depression in well older adults: evaluation of a short form of the CES-D (Center for Epidemiologic Studies Depression Scale). Am J Prev Med 1994; 10: 77-84.

114. Hamilton M. A rating scale for depression. J Neurol Neurosurg Psychiatr 1960; 23: 56-62.

115. Pennypacker LC, Allen RH, Kelly JP, et al. High prevalence of cobalamin deficiency in elderly outpatients. J Am Geriatr Soc 1992; 40: 1197-1204.

116. Healton EB, Savage DG, Brust JC, et al. Neurologic aspects of cobalamin deficiency. Medicine (Baltimore) 1991; 70: $229-245$.

117. Martin DC, Francis J, Protetch J, et al. Time dependency of cognitive recovery with cobalamin replacement: report of a pilot study. J Am Geriatr Soc 1992; 40: 168-172.

118. Cunha UG, Rocha FL, Peixoto JM, et al. Vitamin B12 deficiency and dementia. Int Psychogeriatr 1995; 7: 85-88.

119. Teunisse S, Bollen AE, van Gool WA, et al. Dementia and subnormal levels of vitamin B12: effects of replacement therapy on dementia. J Neurol 1996; 243: 522-529.

120. Bernard MA, Nakonezny PA, Kashner TM. The effect of vitamin B12 deficiency on older veterans and its relationship to health. J Am Geriatr Soc 1998; 46: 1199-1206.

121. Crystal HA, Ortof E, Frishman WH, et al. Serum vitamin B12 levels and incidence of dementia in a healthy elderly population: a report from the Bronx Longitudinal Aging Study. J Am Geriatr Soc 1994; 42: 933-936.

122. White L, Petrovitch H, Ross GW, et al. Prevalence of dementia in older Japanese-American men in Hawaii: The Honolulu-Asia Aging Study. JAMA 1996; 276: 955-960.

123. Clarfield AM. The reversible dementias: do they reverse? Ann Intern Med 1988; 109: 476-486.

124. Weytingh MD, Bossuyt PM, van Crevel H. Reversible dementia: more than $10 \%$ or less than $1 \%$ ? A quantitative review. J Neurol 1995; 242: 466-471.

125. Green R, Kinsella LJ. Current concepts in the diagnosis of cobalamin deficiency. Neurology 1995; 45: 1435-1440.

126. Robuschi G, Safran M, Braverman LE, et al. Hypothyroidism in the elderly. Endocr Rev 1987; 8: $142-153$.

127. Bagchi N, Brown TR, Parish RF. Thyroid dysfunction in adults over age 55 years. A study in an urban US community. Arch Intern Med 1990; 150: 785-787.

128. Luboshitzky R, Oberman AS, Kaufman N, et al. Prevalence of cognitive dysfunction and hypothyroidism in an elderly community population. Isr J Med Sci 1996; 32: 60-65.

129. Osterweil D, Syndulko K, Cohen SN, et al. Cognitive function in non-demented older adults with hypothyroidism. J Am Geriatr Soc 1992; 40: 325-335.

130. Lindeman RD, Schade DS, LaRue A, et al. Subclinical hypothyroidism in a biethnic, urban community [In Process Citation]. J Am Geriatr Soc 1999; 47: 703-709.

131. Ganguli M, Burmeister LA, Seaberg EC, et al. Association between dementia and elevated TSH: a community-based study. Biol Psychiatry 1996; 40: 714-725.

132. Clarnette RM, Patterson CJ. Hypothyroidism: does treatment cure dementia? J Geriatr Psychiatry Neurol, $1994 ; 7: 23-27$.

133. St Louis ME, Wasserheit JN. Elimination of syphilis in the United States. Science 1998; 281: 353-354.[Full Text]

134. Bachman DL, Wolf PA, Linn RT, et al. Incidence of dementia and probable Alzheimer's disease in a general population: the Framingham Study. Neurology 1993; 43: 515-519.

135. Fillenbaum GG, Heyman A, Huber MS, et al. The prevalence and 3-year incidence of dementia in older black and white community residents. J Clin Epidemiol 1998; 51: 587-595.

136. Hebert LE, Scherr PA, Beckett LA, et al. Age-specific incidence of Alzheimer's disease in a community population. JAMA 1995; 273: 1354-1359.

137. Rocca WA, Cha RH, Waring SC, et al. Incidence of dementia and Alzheimer's disease: a reanalysis of data from Rochester, Minnesota, 1975-1984. Am J Epidemiol 1998; 148: 51-62.

138. Stern Y, Gurland B, Tatemichi TK, et al. Influence of education and occupation on the incidence of Alzheimer's disease. JAMA 1994; 271: 1004-1010.

139. Bachman DL, Wolf PA, Linn R, et al. Prevalence of dementia and probable senile dementia of the Alzheimer type in the Framingham Study. Neurology 1992; 42: 115-119.

140. Evans DA, Funkenstein HH, Albert MS, et al. Prevalence of Alzheimer's disease in a community population of older persons. Higher than previously reported. JAMA 1989; 262: 2551-2556.

141. Graves AB, Larson EB, Edland SD, et al. Prevalence of dementia and its subtypes in the Japanese American population of King County, Washington state. The Kame Project. Am J Epidemiol 1996; 144: 760-771.

142. Hendrie HC, Osuntokun BO, Hall KS, et al. Prevalence of Alzheimer's disease and dementia in two communities: Nigerian Africans and African Americans. Am J Psychiatry 1995; 152: 1485-1492.

143. Kokmen E, Beard CM, Offord KP, et al. Prevalence of medically diagnosed dementia in a defined United States population: Rochester, Minnesota, January 1, 1975. Neurology 1989; 39: 773-776.

144. Pfeffer RI, Afifi AA, Chance JM. Prevalence of Alzheimer's disease in a retirement community. Am J Epidemiol 1987; 125: 420-436.

145. Canadian study of health and aging: study methods and prevalence of dementia. CMAJ 1994; 150: 899-913.

146. Powell AL, Coyne AC, Jen L. A retrospective study of syphilis seropositivity in a cohort of demented patients. Alzheimer Dis Assoc Disord 1993; 7: 33-38.

147. Siu AL. Screening for dementia and investigating its causes. Ann Intern Med 1991; 115: 122-132. 


\section{Neurology}

\section{Practice parameter: Diagnosis of dementia (an evidence-based review): Report of the Quality Standards Subcommittee of the American Academy of Neurology}

D. S. Knopman, S. T. DeKosky, J. L. Cummings, et al.

Neurology 2001;56;1143-1153

DOI 10.1212/WNL.56.9.1143

\section{This information is current as of May 8, 2001}

Updated Information \&

Services

Supplementary Material

References

Citations

Permissions \& Licensing

Reprints including high resolution figures, can be found at:

http://n.neurology.org/content/56/9/1143.full

Supplementary material can be found at:

http://n.neurology.org/content/suppl/2001/04/25/56.9.1143.DC1

This article cites 145 articles, 47 of which you can access for free at: http://n.neurology.org/content/56/9/1143.full\#ref-list-1

This article has been cited by 68 HighWire-hosted articles: http://n.neurology.org/content/56/9/1143.full\#\#otherarticles

Information about reproducing this article in parts (figures,tables) or in its entirety can be found online at:

http://www.neurology.org/about/about_the_journal\#permissions

Information about ordering reprints can be found online:

http://n.neurology.org/subscribers/advertise

Neurology ${ }^{\circledR}$ is the official journal of the American Academy of Neurology. Published continuously since 1951, it is now a weekly with 48 issues per year. Copyright . All rights reserved. Print ISSN: 0028-3878. Online ISSN: 1526-632X.

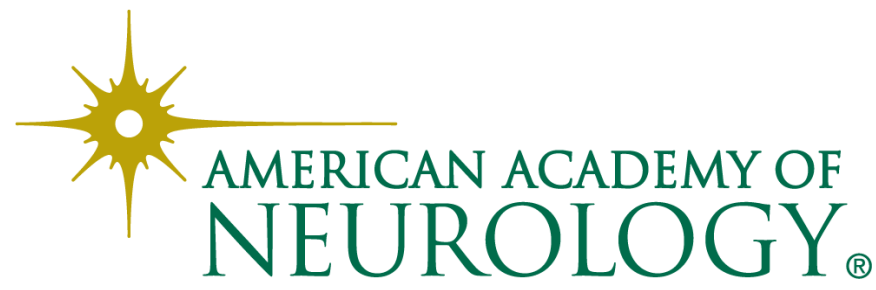

